\title{
論文
}

$\mathrm{INS} /$ 비전 센서 통합 시스템을 이용한 정밀 상대 위치 추정

천세범*, 원대희*, 강태삼*, 성상경*, 이은성**, 조진수***, 이영재*

\section{Estimation of Precise Relative Position using INS/Vision Sensor Integrated System}

Sebum Chun*, Dae Hee Won*, Taesam Kang*, Sangkyung Sung*, Eunsung Lee**, Jinsoo Cho $* * *$ and Young Jae Lee*

\begin{abstract}
GPS can provide precise relative navigation information. But it needs a reference station in a close range and is effected by satellite observation environment. In this paper, we propose INS and Vision sensor integrated system with a known landmark geometry. This system is supposed to overcome problems of GPS only system. Using the proposed method, a relative navigation is available without a GPS reference station. The only need for the proposed system is a landmark image which is drawn on the ground. We conduct simple simulation to check the performance of this method. As a result, we confirm that it can improve the relative navigation information.

\section{초 록}

GPS는 정밀한 상대 항법 정보를 제공해 줄 수 있으나 해당 지역에 기준국이 설치되어 있어야 하고 위성 관측 환경에 영향을 받는다는 단점이 있다. 본 논문에서는 이러한 GPS 단독 사용 시의 한계를 극복하기 위해 사전에 알고 있는 랜드 마크의 기하학적인 배열을 이용한 INS/비전 센서 통합 시스템을 제안한다. 제안된 방법은 사전에 그려진 랜드 마크 의 이미지만 있으면 GPS 기준국 없이도 상대 항법 정보를 제공할 수 있다. 제안된 시스 템은 간단한 시뮬레이션에 의해 성능을 검증하였으며, 이러한 결과 상대 항법 정보를 향 상 시킬 수 있음을 확인하였다.
\end{abstract}

Key Words : Vision Sensor (비전 센서), Relative Navigation (상대 항법), GPS, Particle Filter (파티클 필터)

\section{I. 서 론}

항법 정보를 필요로 하는 다양한 분야에서 절 대 위치만큼이나 대상 지점과의 상대 위치 정보

†2008년 1월 4일 접수 2008년 8월 1일 심사완료

* 정회원, 건국대학교 항공우주정보시스템공학과

교신저자, E-mail : younglee@konkuk.ac.kr

서울시 광진구 화양동 1 번지

** 정회원, 한국항공우주연구원

*** 정회원, 한양대학교 기계공학부
가 중요하게 취급된다. 특히 고정익이나 회전익 항공기의 운영에서 지면의 특정지점과의 상대위 치를 정확히 판단하는 것은 이착륙과정이나 다양 한 작업 수행 시 매우 중요하다고 할 수 있다.

상대 위치 정보를 제공하기 위한 방법으로는 다양한 방법이 개발되어 있다. GPS RTK (Real Time Kinematic)는 수 $\mathrm{cm}$ 이하의 오차를 갖는 상 대 위치 정보를 제공해 주는 가장 확실한 방법이 다. 이러한 방법은 현재 기술 수준으로도 안정적 인 위치 정보를 제공하는 것이 가능하나, 기본적 
으로 고정밀의 항법 정보가 필요한 지점에 기준 국이 운영되어야 하며 일반적인 GPS 수신기보다 고가의 수신기를 요구한다는 단점이 있다. 또한 실시간으로 지상 기준국과 통신을 수행하여야 하 므로 정보 제공 주기를 높이기 어렵고 데이터 통 신을 위한 장비 등 시스템 가격도 높다는 단점이 있다. 더욱이 군용 시스템일 경우는 통신을 위해 전파를 발산하여야 하기 때문에 자신의 위치가 노출될 위험이 있다. 또한 GPS는 궤도상의 위성 에서 송신하는 신호를 수신하여 이용하기 때문에 위성이 관측되지 않는 지역이나 관측 환경이 불 량한 지역에서는 항법 정보를 얻을 수 없는 경우 도 있다.

이러한 방법들의 단점을 보완하기 위해 비전 센서를 이용하는 방법들이 연구되어왔다. 특히, 최근의 비전 센서와 프로세서의 발달로 인해 항 법분야에서의 비전 센서의 응용에 대한 연구가 활발히 진행되고 있다. Backer, Sharp [1, 2] 등에 의해 외부 환경에 설치된 인위적인 지상 표식 (artificial land mark)를 이용하여 항법 정보를 얻는 방법이 제안되었다. Sharp는 관측된 표적의 선형 최적화를 통해 비선형 최적화 방법의 초기 점을 제공하는 방식으로 위치 및 자세 정보를 추 정해 내었으며. Backer는 천정에 설치된 표적이 관측되는 영역을 이용하여 위치를 추정해 내는 방법을 제시하였다. Backer와 Sharp의 연구가 고 정된 표적을 추정하는 대신, Coelho [3]는 비행 선에 부착된 표적을 이용하여 비행선의 자세와 위치를 추정하는 연구를 수행하였다. Hubbard [4]는 비전 센서와 레이저를 이용하여 얻어진 지 상 표적의 정보를 이용하여 무인 헬기의 이착륙 시스템을 개발하였다.

본 논문에서는 정밀 상대 항법 정보를 얻기 위한 비전센서/INS 통합 필터를 구성하였다. 제 안된 방법은 사전에 알려져 있는 기하학적인 형 상의 랜드 마크를 표시해 주는 것만으로 3 차원 항법을 수행 할 수 있다는 장점이 있다. 이 과정 에서 영상 정보가 갖는 비선형 관측 모델을 극복 하기 위해 파티클 필터 (particle filter)를 적용하 여 Sharp가 제시한 방법과 달리 비선형 모델을 직접 이용하였다. 또한 레이저를 이용해 거리 측 정 정보를 이용한 Hubbard와는 달리 비전 센서 의 정보만을 사용하여 상대 위치 정보를 추정해 내었다.

본 논문의 2장에서는 $\mathrm{INS} /$ 비전 센서 통합 시 스템에 사용될 파티클 필터의 특징과 구성에 대 해서 소개하고, 3장에서는 INS/비전 센서 통합 시스템의 구성에 대해 언급한다. 4 장은 본 논문
에서 사용될 통합 방식 및 필터 구조에 대해 언 급한다. 5장, 6장에서는 성능 평가를 위한 시뮬레 이션을 구성하고 결과에 대해 언급한다.

\section{ㅍ. 파티클 필터}

파티클 (particle) 필터는 점밀도 확률 분포 (point mass probability distribution) 방식에 기 초한 순차적 몬테카를로 (Monte Carlo) 기법을 이용한 준 최적 (sub-optimal) 필터이다. 이때 점 밀도 (point mass)를 파티클 (particle)이라고 한 다. 파티클 필터는 1950년대 이래로 계속 연구되 고 있으나 막대한 연산 량과 메모리 소모는 파티 클 필터의 구현을 불가능하게 하였다. 그러나 최 근의 급속한 컴퓨터 발달은 파티클 필터의 구현 을 가능하게 만들었으며, 이로 인하여 관련된 연 구가 활발히 진행되고 있다 $[5,6]$.

파티클 필터도 일반적인 필터의 추정 방식과 동 일하게 측정치 갱신과 시간 갱신의 과정을 가지 고 있다. 그러나 파티클 생성과정이나 퇴화 등의 문제로 인해 일반적인 칼만 필터 등과는 다른 리 샘플링 (resampling)이라는 특이한 과정을 갖게 된다.

파티클 필터는 칼만 필터와 달리 잡음 분포가 정상 분포가 아니거나 시스템 모델이 비선형인 경우도 적용 가능한 필터로써 측정 모델을 구성 하기 어렵고 정상 분포가 아닌 경우에도 상태 추 정이 가능하다는 특징이 있다. 이러한 이유로 본 논문에서는 비선형 관측 모델을 갖는 비전 센서 를 이용하여 INS의 항법 오차를 추정해 내기 위 해 파티클 필터를 적용하였다.

\section{III. 대상 시스템 분석}

본 절에서는 비전 시스템 및 기타 센서를 이 용하여 무인 항공기의 근거리 위치 및 헤딩 추정 을 위한 시스템을 제안하고 설명한다.

\section{1 대상 시스템 분석}

비전센서를 이용한 근거리 위치 추정 시스템 의 구성은 그림 1 과 같다.

시스템은 IMU (Inertia Measurement Unit), 그리고 지면을 촬영 할 수 있도록 설치된 비전 센서로 구성된다. 비행체에 탑재된 비전 센서의 광축은 $z$ 축과 일치하고 있으며 비전 센서의 내부 파라미터 (intrinsic parameter)는 사전에 추정되 어 있다고 가정한다[7, 8]. 


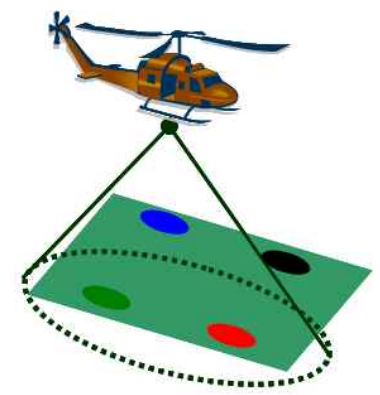

그림 1. 시스템 개요

지면에는 사전에 기하학적 형상이 알려져 있는 랜드 마크 (land mark)가 그려져 있다. 랜드 마 크를 이용하는 경우 사전의 랜드 마크 위치 측량 이 문제가 될 수도 있으나 최종적으로 요구되는 항법 결과가 랜드 마크에 대한 상대 위치 정보이 기 때문에 절대 위치보다는 랜드 마크의 기하학 적인 형상 등이 상대적으로 더 중요하다. 그러므 로 일정 수준 내에서 정확도를 만족시키는 랜드 마크의 정보만 있으면 원하는 수준의 상대 위치 정보를 얻어 낼 수 있다.

\section{2 좌표계 정의}

$\mathrm{INS} /$ 비전 센서 통합 필터에서는 항법 좌표계 (navigation frame, 이하 $\mathrm{n}$-frame), 동체 좌표계 (body frame, 이하 b-frame), 센서 좌표계 (sensor frame, 이하 $\mathrm{s}$-frame)가 사용된다[9, 10]. 각 좌표계의 상관관계는 그림 2 와 같다.

\section{3 랜드 마크 추적}

비전 센서 정보를 이용하기 위해서는 관측된 랜드 마크 포인트를 구별해 내고 움직임을 추적 할 수 있어야 한다. 랜드 마크 포인트의 추적을

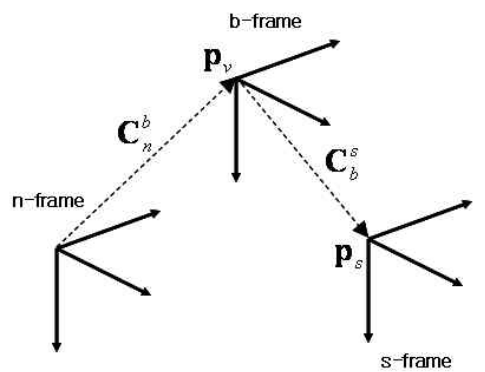

$C_{n}^{b}$ :Rotational transformation matrix from navigation to body frame

$C_{b}^{s}$ :Rotational transformation matrix from body to sensor frame

$\mathbf{p}_{\mathrm{v}}$ : Positioning vector of vehicle

$\mathbf{p}_{\mathrm{s}}:$ Sensor lever arm

그림 2. 좌표계간 상관관계

\section{4 랜드 마크 추적}

비전 센서 정보를 이용하기 위해서는 관측된 랜드 마크 포인트를 구별해 내고 움직임을 추적 할 수 있어야 한다. 랜드 마크 포인트의 추적을 용이하기 위해서는 랜드 마크 자체가 관측되는 영상의 다른 부분과 구별이 용이해야 하며 자세 나 위치 등에 상관없이 동일한 추적 성능을 제공 할 수 있어야 한다.

그림 3 에서 제시한 랜드 마크의 예는 원 모양 을 랜드 마크를 하나의 포인트로 설정하고, 이러 한 포인트로 사각형을 이루는 형태이다. 이러한 경우 랜드 마크의 추적은 먼저 이진화를 수행한 뒤 라벨링 (labeling) 알고리즘을 적용하여 랜드 마크의 각 포인트를 구별해 내며 매 시간 획득되 는 영상을 기반으로 랜드 마크 포인트의 추적을 수행한다. 이와 같이 단순한 형태를 이용해 랜드 마크를 구성하는 방법 외에 구별이 용이한 특수한 패턴을 만들어 내는 방법 등이 적용 가능하다[2].

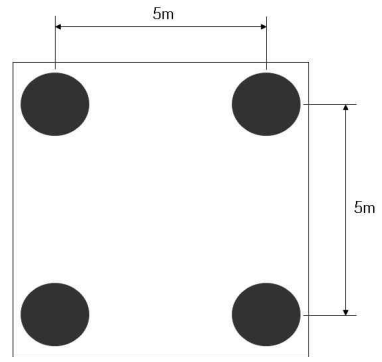

그림 3. 랜드 마크 이미지의 예

\section{5 시스템/측정 모델}

비전 시스템의 시스템 모델은 관성 항법 시스 템의 오차 모델을 사용하며 식 (6)과 같이 나타 낼 수 있다[11].

$\mathbf{X}_{k+1}=\boldsymbol{\Phi}_{k} \mathbf{X}_{k}+\mathbf{G}_{k} \mathbf{w}_{k}$

$\mathbf{\Phi}_{k}=\left[\begin{array}{ccc}\mathbf{I} & \mathbf{I} \cdot \Delta t & \\ & \mathbf{I} & {\left[\mathbf{f}_{n} \times\right] \cdot \Delta t} \\ & & \mathbf{I}\end{array}\right], \mathbf{G}_{k}=\left[\begin{array}{cc}\mathbf{0} & \mathbf{0} \\ \mathbf{C}_{b}^{n} & \mathbf{0} \\ \mathbf{0} & -\mathbf{C}_{b}^{n}\end{array}\right], \mathbf{w}_{k}=\left[\begin{array}{l}\sqrt{\Delta t} \mathbf{w}_{a} \\ \sqrt{\Delta t} \mathbf{w}_{g}\end{array}\right]$

$\mathbf{X}_{k+1}=\left[\begin{array}{lll}\delta \mathbf{x} & \delta \mathbf{v} & \delta \boldsymbol{\psi}\end{array}\right]^{T}$

여기서,

$\mathbf{f}_{n}$ : acceleration vector in $\mathrm{n}$-frame

$\mathbf{w}_{a}$ :accelerometer error

$\mathbf{w}_{g}$ :accelerometer error

$\delta \mathbf{x}$ :position error

$\delta \mathbf{v}$ : velocity error

$\delta \psi$ :platform tilting error 
측정 모델은 관측된 랜드 마크에서의 각각의 포 인트들에 대한 방위각과 고도 정보를 이용하게 된다. 관측 모델은 식 (7)과 같이 비선형 식으로 나타나게 된다. 이때 측정 잡음은 $\mathrm{CCD}$ 평면상의 오차로 나타나기 때문에 합 (additive) 형태의 오 차로 나타나게 된다.

$$
\begin{aligned}
& \mathbf{z}_{k}=\mathbf{h}_{k}\left(\mathbf{X}_{k}\right)+\mathbf{v}_{k} \\
& \mathbf{v}_{k} \sim N(0, R)
\end{aligned}
$$

여기서,

$\mathbf{X}_{k}=\left[\begin{array}{ll}\mathbf{x}_{v}^{n} & \mathbf{x}_{L M}^{n}\end{array}\right]^{T}$

식 (8)은 랜드 마크에서 각각의 포인트들의 위치 를 센서 좌표계에 대해 나타낸 것이다.

$$
\mathbf{x}_{L M}^{s}=C_{b}^{s}\left(C_{n}^{b}\left(\mathbf{x}_{L M}^{n}-\mathbf{x}_{v}^{n}\right)-\mathbf{p}_{s}\right)
$$

여기서,

$\mathbf{x}_{L M}^{s}$ :Landmark position in s-frame

$\mathbf{x}_{L M}^{n}$ :Landmark position in $\mathrm{n}$-frame

$\mathbf{x}_{v}^{n}$ :Vehicle position in $\mathrm{n}$-frame

$\mathbf{p}_{s}:$ Sensor lever arm

센서 좌표계에 대해 표현된 랜드마크 포인트의 위치와 측정치와는 식 (9)와 같은 관계를 갖는다 $[12,13]$.

$$
\mathbf{z}=\left[\begin{array}{c}
\tan ^{-1}\left(\frac{y}{x}\right) \\
\tan ^{-1}\left(\frac{z}{\sqrt{x^{2}+y^{2}}}\right)
\end{array}\right]
$$

여기서,

$$
\begin{aligned}
& \mathbf{x}_{L M}^{s}=\left[\begin{array}{l}
x \\
y \\
z
\end{array}\right], \mathbf{z}=\left[\begin{array}{l}
\psi \\
\theta
\end{array}\right] \\
& \psi: \text { Feature Point Bearing } \\
& \theta \text { :Feature Point Elevation }
\end{aligned}
$$

\section{$\mathrm{IV}$. INS/비전 센서 통합 필터 구성}

지금까지 언급한 INS/비전 센서를 이용하여 상대 위치를 추정하는 방식에는 시스템의 상태 벡터를 직접 이용하는 직접 (direct) 방식과 오차 만을 추정하는 간접 (indirect)방식이 있다. 본 논 문에서는 간접 방식을 이용하여 필터를 구성하였 다. 이때 영상처리는 필터 외부에 존재하는 모듈 에서 독립적으로 수행된다고 가정하였다. 필터에 서 추정된 항법 오차는 외부에서 높은 주기로 작

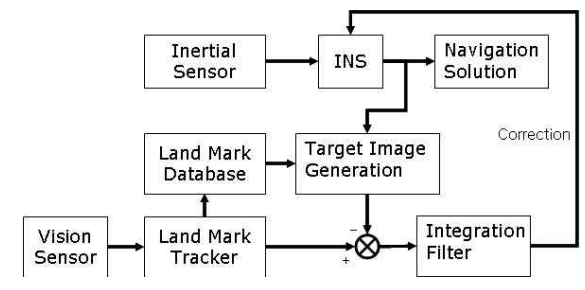

그림 4. INS/비전 센서 통합 시스템 구조

하는 INS에 피드백 되어 보상해 주는 앞먹임 (feed forward) 구조를 가지고 있다. 그림 4는 이 러한 INS/비전 센서 통합 필터를 나타낸다[14].

\section{$\mathrm{V}$. 시뮬레이션 구성}

제안된 INS/비전 통합 시스템의 성능 분석을 위한 시뮬레이션을 수행하였다. 이 과정에서 주 어진 성능의 관성 센서에서 비전 센서의 성능 변 화에 따른 항법 성능의 변화에 대해 분석하였다.

\section{1 시뮬레이션 개요}

$\mathrm{INS} /$ 비전 통합 시스템의 성능 분석을 위해 일 정한 영역에서 랜드 마크를 포착하였을 경우 제 안된 INS/비전 통합 시스템을 위한 시뮬레이션 을 수행하였다. 이 과정에서 영상 처리 및 랜드 마크 포인트의 추적은 별도의 모듈에서 수행된다 고 가정하고 비행체에 탑재된 비전 센서에서는 랜드 마크 포인트의 방위각과 고도 정보만을 제 공해 준다고 가정하였다.

비행체의 움직임은 $5 \mathrm{~m}$ 의 고도에서 반경 $10 \mathrm{~m}$ 의 원형 궤적을 반복해서 움직이도록 하였다. 비 행 속력은 전 구간에서 일정하게 $7 \mathrm{~m} / \mathrm{s}$ 를 유지하 였다. 지면에 표시된 랜드 마크 포인트의 형태는 사각형으로 배치하였으며, 각 변의 길이는 $5 \mathrm{~m}$ 이 다. 비전 센서는 비행체의 수직 하방을 관측하도 록 설정되었다. 비행체의 움직임과 랜드 마크 포 인트의 배치는 그림 5 와 같다.

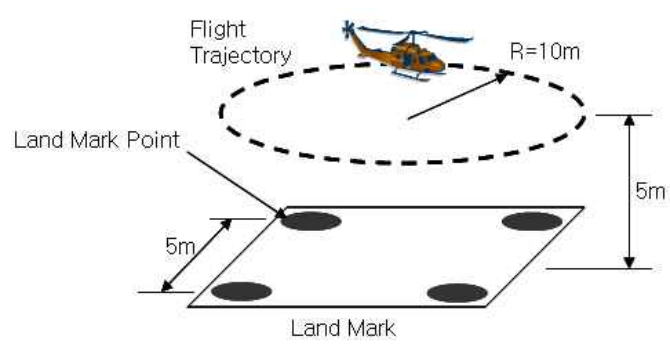

그림 5. 시뮬레이션 환경 구성 


\section{2 적용 센서 사양}

시뮬레이션에 사용된 관성 센서는 MEMS 급 의 저급 센서를 사용하였으며 사전에 비정렬 (Misalignment) 오차와 바이어스 (bias) 등은 일 정 수준 이상으로 보상되어 있다고 가정하였다. 이러한 관성 센서의 측정치를 이용하여 INS를 구성하였으며 연산 주기는 0.01초로 설정하였다. 표 1 은 관성 센서의 사양을 나타낸 것이다.

비전 센서는 사전에 적절한 방법으로 내부 파 라미터들이 추정되어 있다. 비전 센서의 관측치 는 랜드 마크의 방위각 (azimuth) 및 고도각 (elevation)으로 제공되게 되는데 이때 발생하는 오차는 $\mathrm{CCD}$ 와 렌즈의 영향을 받아 발생하게 되 며, 해상도와 밀접한 관계가 있다. 비전 센서의 측정 오차는 이러한 방위각과 고도각 정보에 합 의 형태로 더해지게 되며 0.1도에서 20도까지 비 전 센서 측정 오차를 변경 시키면서 시스템 성능 을 분석하였다. 비전 센서의 설치 과정 등에서 발생하는 오차는 무시하였다.

\section{$\mathrm{VI}$. 성능 분석}

설계된 필터의 성능 분석을 위해 시뮬레이션 을 수행하였다. 그림 6, 7은 INS 단독으로 항법 을 수행한 추정 결과와 이때의 오차이다. 시뮬레 이션 시간은 100 초로 저급 관성센서를 사용하였 기 때문에 짧은 시간임에도 불구하고 매우 크게 발산하고 있음을 확인 할 수 있다.

\section{표 1. 관성 센서 사양}

\begin{tabular}{|l|l|l|}
\hline & $\begin{array}{l}\text { Standard } \\
\text { Deviation }\end{array}$ & Drift/Bias \\
\hline Gyro & $1 \mathrm{deg} / \mathrm{s}$ & $<1800 \mathrm{deg} / \mathrm{hr}$ \\
\hline Accelerometer & $1 \mathrm{~m} / \mathrm{s}^{2}$ & $<0.01 \mathrm{~m} / \mathrm{s}$ \\
\hline
\end{tabular}

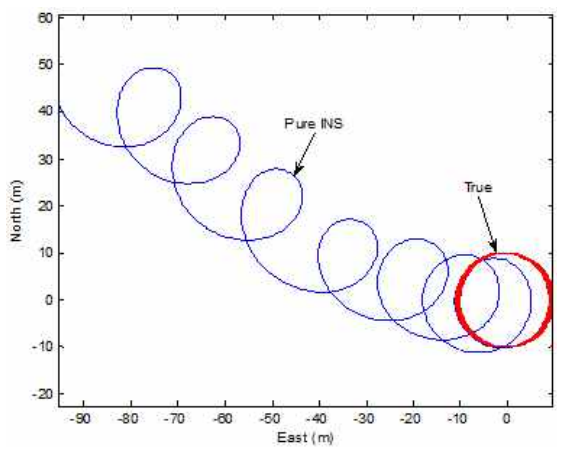

그림 6. INS 단독 추정 결과

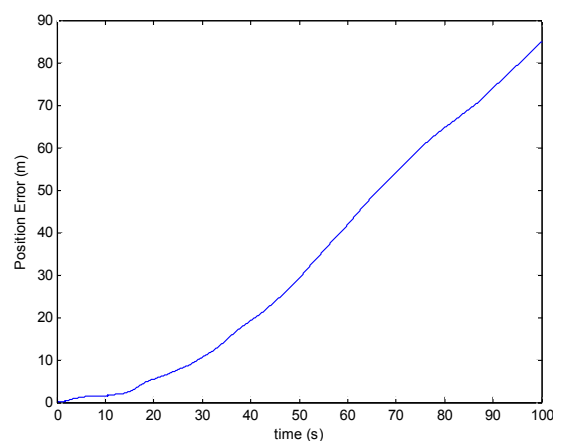

그림 7. INS 단독 항법 오차

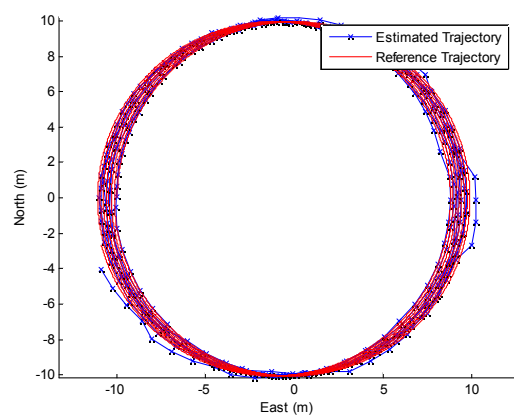

그림 8. INS/GPS 통합 시스템 추정 결과

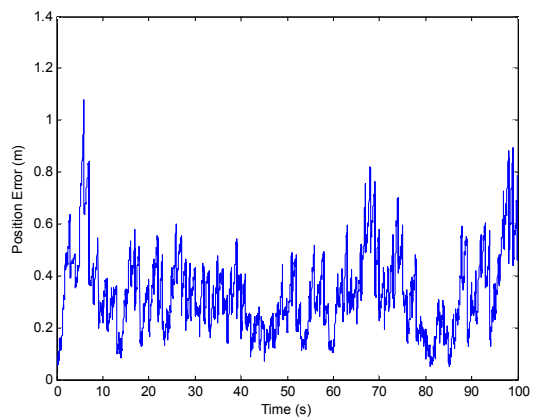

그림 9. INS/GPS 통합 시스템 항법 오차

그림 8은 대상 지역에 GPS 기준국을 설치하고 GPS 반송파를 이용해 얻을 수 있는 정밀 위치를 이용한 결과이다. 고정밀의 GPS 위치 정보를 이용하는 경우 높은 정밀도의 위치 해를 얻을 수 있다. 그림 9 는 이때의 위치 추정 오차이다.

그림 10은 INS/비전 센서 통합 항법을 적용한 것으로 비전 센서의 오차는 1 도(표준 편차)의 오 차를 갖도록 하였다. 이 결과에서 INS 단독 항법 에 비해 시간에 따른 발산이 거의 억제되고 있음 을 확인 할 수 있고, 참 궤적과 거의 일치하는 위치 해를 제공하는 것을 볼 수 있다. 그림 11은 이때의 위치 오차이다. 이 결과에서 GPS 정밀 위치 해를 이용한 경우에 비교해 볼 때, 지상 장 


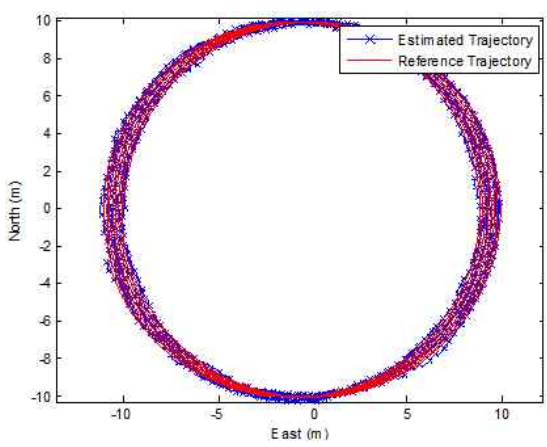

그림 10. INS/비전 센서 통합 시스템 추정 결과

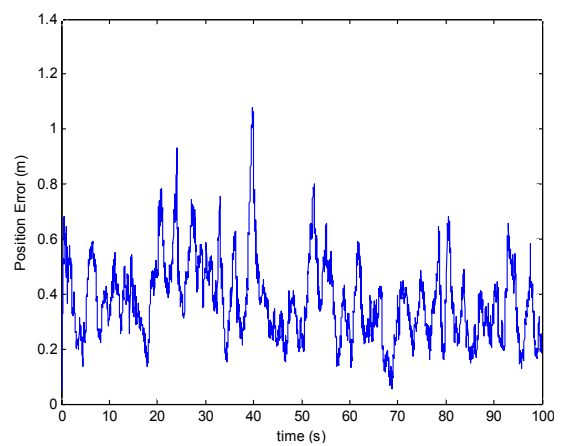

그림 11. INS/비전 센서 통합 시스템 항법 오차

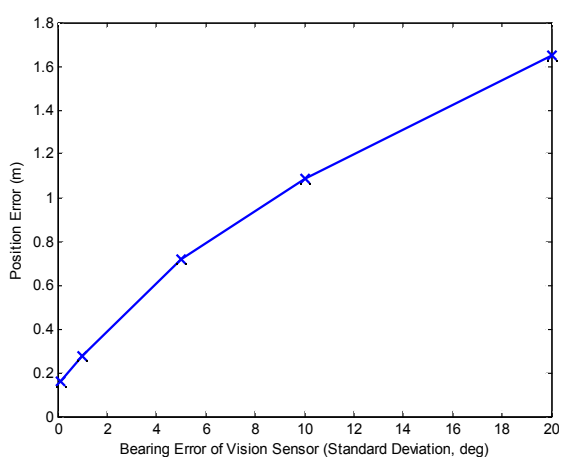

\section{그림 12. 비전 센서 정밀도에 따른 항법오차}

비의 정보를 이용하지 않음에도 불구하고 거의 유사한 수준의 위치 정보를 제공해 주고 있음을 확인 할 수 있다.

비전 센서의 측정 오차나 랜드 마크 포인트의 추적 오차에 대한 민감도를 분석하기 위해 비전 센서의 측정 오차 크기를 다르게 하며 동일한 시 뮬레이션을 수행하였다. 그림 12는 비전 센서 오차 변화에 따른 시스템 추정 성능을 비교한 것이다.

이 결과에서 볼 수 있듯이 비전 센서에서 제 공한 측정치의 잡음이 커지더라도 단순 발산 하 는 INS 단독 항법에 비해 제한된 오차를 보여주 고 있는 것을 확인 할 수 있다.

\section{VII. 결 론}

본 논문에서는 임의의 목표 지점과의 상대 항 법 정보를 제공해 주기 위한 항법 시스템에 대해 연구하였다. 이 과정에서 사전에 정해진 기하학 적 형상을 지니고 지상에 그려진 랜드 마크를 이 용하는 INS/비전 센서 통합 시스템을 제안하였 다. 제안한 시스템은 GPS에 의지하지 않음으로 대상 지역에 기준국 설치가 필요 없으며, 위성이 관측되지 않는 환경에서도 충분히 응용이 가능하 다는 장점이 있다. 이러한 비전 센서를 기반에 둔 시스템의 비선형 관측 모델에 대응하기 위해 파티클 필터를 적용하였다. INS 단독 항법의 경 우 및 GPS를 이용한 경우와 항법 성능을 비교하 기 위해 시뮬레이션을 구성하여 성능을 확인하였 다. 이 결과 INS 단독 항법과 달리 제한된 오차 를 가짐을 확인하였고, GPS를 이용한 경우와도 거의 유사한 항법 오차를 갖는 것을 확인하였다.

본 논문에서 제안된 INS/비전센서 통합 시스 템은 지상의 특정 지점과의 상대 항법 정보가 필 요한 경우, 고가의 GPS 관련 장비를 대체 할 수 있는 항법 방식이다. 특히 GPS가 적용 불가능한 실내에서도 사용 가능하므로 그 응용 범위를 확 대 할 수 있을 것이다.

\section{후 기}

이 논문은 2007년도 정부(과학기술부)의 재원으 로 한국과학재단의 지원을 받아 수행된 연구임.

\section{참고문헌}

1) Craig Becker, "Reliable Navigation Using Land marks", Proceedings of IEEE International Conference on Robotics and Automation, 1995, pp. 401 406.

2) Courtney S. Sharp, "A Vision System for Landing an Unmanned Aerial Vehicle", Proceedings of the IEEE International Conference on Robotics and Automation,Vol. 2, 2001, pp. 1720 1727.

3) L. S. Coelho, "Pose Estimation of Autonomous Dirigibles Using Artificial Landmarks", Proceedings of IEEE International Conference on Robotics and Automation, Vol. 4, May 1999, pp. 2584 2589.

4) D. Hubbard, "Performance Evaluation of 
Vision-based Navigation and Landing on a Rotorcraft Unmanned Aerial Vehicle", IEEE Workshop on Application of Computer Vision, Feb 2007, pp. 5.

5) Branko Ristic, Beyond the Kalman Filter, ArtechHouse, 2004.

6) Arnaud Doucet, Sequential Monte Carlo Methods in Practice, Springer, 2001.

7) Zhengyou Zhang, "Flexible Camera Calibration By Viewing a Plane From Unknown Orientations", The Proceedings of the 7th IEEE International Conference on Computer Vision, Vol.1, Sep 1999, pp. 666-673.

8) Richard Hartley, Multiple View Geometry, 2nd Ed, Cambridge, 2003.

9) Averil B. Chatfield, Fundamentals of High Accuracy Inertial Navigation, American
Institute of Aeronautics and Astronautics, 1997.

10) Jay Farrell, The Global Positioning System and Inertial Navigation, McGraw-Hill, 1998.

11) Robert Grover Brown, Introduction to Random Signals and Applied Kalman Filtering, 3rd Ed, John Wiley \& Sons, 1997.

12) Mitch Bryson, "Building a Robust Implementation of Bearing-only Inertial SLAM for a UAV", Journal of Field Robotics 24(1/2), 2007, pp. 113-143.

13) Hugh Durrant-Whyte, "Simultaneous Localization and Mapping: Part-I,II", Robotics \& Automation Magazine, IEEE, Vol.13, Issue2, June 2006, pp. 99-110.

14) Peter S. Maybeck, Stochastic Models, Estimation, and Control, NavtechBook, 1994. 